DOI: $10.17957 / \mathrm{IJAB} / 15.1786$

http://www.fspublishers.org

\title{
Molecular Characteristics and Adhesion Activity of a Novel Protein ADP1 of Arthrobotrys oligospora to Nematodes
}

\author{
$\mathrm{Li} \mathrm{Jie}^{1 \dagger}$, Chen Shuangqing ${ }^{1 \dagger}$, Li Zhiyuan ${ }^{1 \dagger}$, Wang Lixia ${ }^{1}$, Shang Yunxia ${ }^{1}$, Gong Shasha ${ }^{1}$, Xiao Chencheng ${ }^{1}$, Zhang Kai ${ }^{1}$, \\ Zhang Xingxing ${ }^{2}$, Cai Xuepeng, ${ }^{3}$ Qiao Jun ${ }^{1}$ and Meng Qingling ${ }^{1^{*}}$ \\ ${ }^{1}$ College of Animal Science and Technology, Shihezi University, Shihezi, Xinjiang, 832003, P. R. China \\ ${ }^{2}$ Institute of Animal Science and Veterinary Research, Xinjiang Academy of Agricultural and Reclamation Science, Shihezi, \\ Xinjiang, 832003, P. R. China \\ ${ }^{3}$ State Key Lab of Veterinary Etiological Biology, Lanzhou Veterinary Research Institute, Chinese Academy of Agricultural \\ Sciences, Lanzhou, Gansu, 730046, P. R. China \\ *For correspondence: xjmqlqj@ sina.com \\ † Contributed equally to this work and are co-first authors \\ Received 15 October 2020; Accepted 02 March 2021; Published 10 May 2021
}

\begin{abstract}
Adhesion is a crucial step for nematode-trapping fungi (NTF) predating nematodes. To investigate the function of a novel protein $A D P 1$ in nematode-trapping process, $A D P 1$ gene of a representative NTF-Arthrobotrys oligospora was cloned and the molecular characteristics of this protein were analyzed. Then, the GFP chimeric ADPl (ADPl-GFP) was generated in a $G F P$ expression vector and expressed in Escherichia coli BL21 (DE3) and the recombinant ADP1-GFP (reADP1-GFP) was purified. Incubation of reADPl-GFP with $\mathrm{J} 3$ larvae of Caenorhabditis elegans and Haemonchus contortus showed that reADP1-GFP could adhere nematodes with the strongest adhesion ability at $25^{\circ} \mathrm{C}$, while the reADP1-GFP treated by trypsin completely lost the adhesion ability. Furthermore, the numbers of captured nematodes of A. oligospora treated by antireADP1-GFP serum in the experimental group was significantly lower than that in the control group, which suggests that the nematode-trapping activity of $A$. oligospora is inhibited by anti-ADP1 serum. To the best of our knowledge, this is the first report confirming that ADP1 from A. oligospora can modulate the adherence to C. elegans and H. contortus. The exploration of interaction between $A D P 1$ protein of $A$. oligospora and nematodes provides new insights into the process of invasion and molecular mechanisms of A. oligospora preying nematode. (C) 2021 Friends Science Publishers
\end{abstract}

Keywords: Arthrobotrys oligospora; Adhesion protein; Fusion protein; ADP1-nematode interactions

\section{Introduction}

Gastrointestinal nematode disease of livestocks is parasitic disease seriously threatening the development of livestock industry and annually causing huge economic losses (Sréter et al. 1994; Tembely et al. 1997; Kaewthamasorn and Wongsamee 2006; Terrill et al. 2012). Currently, the disease is mainly prevented and controlled by chemical drugs. However, long-term use of these chemical drugs at high dosage has drawbacks (drug resistance, drug residues and environmental pollution) and becomes an increasingly prominent issue (Hay et al. 1997; Alvarez et al. 2008). Therefore, it is necessary to seek animal- and environmentfriendly prevention and control methods. Using nematode predators-nematode-trapping fungi (NTF) to achieve the goal is considered as a prospective biological method (Grønvold et al. 1993; Gives and Vazquez-Prats 1994; Bird and Herd 1995; Chandrawathani et al. 1998; Fernández et al. 1999; Flores-Crespo et al. 2003).
NTF, are class fungi of more than 700 species that are able to prey, parasite or colonize nematodes. As the natural nematode predators, NTF can produce predatory organs to capture nematodes, most of their preying processes include identification, attraction, adhesion and degradation (Nordbring-Hertz et al. 2006), among which, adhesion is the most important step for preying nematodes. However, so far, the underlying molecular mechanisms of NTF preying nematodes are still incompletely understood (Liang et al. 2013; Andersson et al. 2014; Liu et al. 2014).

In recent years, the genomes of a number of NTF have been successfully sequenced and their genes related to predation have been studied in depth (Liu et al. 2018; Liang et al. 2013). As a representative of predatory fungi of nematode species, the genome of Arthrobotrys oligospora was first sequenced in 2011. Based on the results, Yang et al. (2011) predicated 17 adhesion-related protein-coding genes and found by qPCR that one of the predicted proteins, named $A D P 1$, was upregulated by 21.7 -fold during their

To cite this paper: Jie L, C Shuangqing, L Zhiyuan, W Lixia, S Yunxia, G Shasha, X Chencheng, Z Kai, Z Xingxing, C Xuepeng, Q Jun, M Qingling (2021). Molecular characteristics and adhesion activity of a novel protein ADP1 of Arthrobotrys oligospora to nematodes. Intl J Agric Biol 25:1249-1254 
predatory organ formation, suggesting that $A D P 1$ may play an important role in the process of A. oligospora trapping nematode (Yang et al. 2011). However, the molecular characteristics and function of $A D P 1$ of A. oligospora is still uncovered. The aim of this study is to analyze the molecular characteristic of a novel $A D P 1$ protein of A. oligospora, and to explore the roles of $A D P 1$ protein in the process of nematode-trapping, thus understanding the biological function of $A D P 1$ of $A$. oligospora in invading nematodes.

\section{Materials and Methods}

\section{Amplification of $A D P 1$ gene of $A$. oligospora}

Based on the full-length $A$. oligospora $A D P 1$ gene sequence with accession number AOL_s00210g23 in GenBank published by Yang et al. (2011), a pair of ADP1 specific primer P1 and P2 was designed. After cultured in liquid LMZ medium (Tiangen, China) at $26^{\circ} \mathrm{C}$ with shaking at 150 rpm for $3 \mathrm{~d}$, A. oligospora XJ-A1 strain was collected and its total RNA was extracted using Trizol (Invitrogen, USA) and reversely transcripted into cDNA using PrimeScript ${ }^{\mathrm{TM}}$ reagent kit (Takara, Japan). The cDNA was then used as the template to amplify $A D P 1$ gene at PCR reaction conditions of $95^{\circ} \mathrm{C}$ for 5 min followed by 30 cycles of $40 \mathrm{~s}$ at $94^{\circ} \mathrm{C}$, $40 \mathrm{~s}$ at $64^{\circ} \mathrm{C}$ and $1 \mathrm{~min}$ at 72 and final $10 \mathrm{~min}$ at $72^{\circ} \mathrm{C}$.

\section{Cloning of ADP1 gene from A. oligospora}

The obtained ADPl gene was recovered using Agarose Gel DNA Fragment Recovery Kit (Takara, Japan) and cloned into pMD18-T vector (Takara, Japan). The correct clones were identified by PCR and digestion with EcoRI and BamHI and further verified by sequencing (BGI, Shenzhen). Four positive clones were sequenced and compared with $A$. oligospora ADP1 gene sequence in GenBank.

\section{Analysis of molecular characteristics of $A D P 1$ protein of A. oligospora}

The amino acid sequence of $A D P 1$ was deduced, and its signal peptide was analyzed by software SignalP 4.1 (https://www.cbs.dtu.dk/services/SignalP/). The transmembrane and domains of this protein were predicted by TMHMM 2.0 and Scanprosite software (https://www.expasr.org/), respectively. Moreover, the secondary and tertiary structures were also predicted by Software Sopma and Swiss-model (https://www.expasr.org/), respectively.

\section{Expression and purification of recombinant protein ADP1-GFP}

The obtained plasmid pT-ADP1 and the expression vector pET28a-GFP were digested with restriction enzymes EcoRI and Hind III, respectively, and the digested vector and targeted $A D P 1$ fragment were ligated at $16^{\circ} \mathrm{C}$ to generate pET28a-GFP-ADP1 recombinant expression vector. The pET28a-GFP-ADP1 and pET28a-GFP plasmids were identified by PCR using specific primers $\mathrm{P} 1-$ $\mathrm{P} 2$ and $\mathrm{P} 1-\mathrm{P} 4$, respectively, and then transformed into $E$. coli BL21 (DE3) for expression. After $6 \mathrm{~h}$ of IPTG (Takara, Japan) induction, cell lysates were subjected to $12 \%$ SDS-PAGE analysis. Then, Western blot analysis was performed by using the mouse anti-reADPl antibody as the primary antibody and HRP-labeled goat anti-mouse antibody (Abcam, USA) as the secondary antibody. The expressed recombinant proteins reADP1-GFP and reGFP were purified using Ni-NTA Spin Kit (Qiagen, Germany) according to the instructions provided by the manufacturer, concentrated with millipore ultrafiltration system (Amicon, USA) and adjusted to $1 \mathrm{mg} / \mathrm{mL} 0.01 \mathrm{M}$ PBS, $\mathrm{pH} 7.2$ solution for future use.

\section{Analysis of interactions between $r e A D P 1-G F P$ and nematode}

Briefly, the infective larva of Caenorhabditis elegans and Haemonchus contortus were prepared as suspensions of 2000 nematodes per $\mathrm{mL}$. Then, $1 \mathrm{~mL}$ of the larval suspension of $C$. elegans and $H$. contortus were incubated with $1 \mathrm{~mL}$ of reADP1-GFP, GFP, bovine serum albumin (BSA) and trypsin-treated reADPI-GFP at $25^{\circ} \mathrm{C}$ for $1 \mathrm{~h}$, respectively. Then, $200 \mu \mathrm{L}$ of each mixture was taken out and centrifuged at $6000 \mathrm{rpm}$ for $1 \mathrm{~min}$ and the collected nematodes were washed with $0.01 \mathrm{M}$ PBS, $\mathrm{pH} 7.2$ for 6 times to be observed under a fluorescent microscope.

\section{Effects of anti- $A D P 1$ antibody on the nematode-trapping activity of $A$. oligospora}

The hyphae were transferred to corn meal agar (CMA) solid medium (17 g corn meal, $10 \mathrm{~g}$ agar and $2 \mathrm{~g} \mathrm{~K}_{2} \mathrm{HPO}_{4}$ in $1 \mathrm{~L}$ of water, adjusted to $\mathrm{pH} 7$ using $1 \mathrm{M} \mathrm{NaOH}$ ) containing $0.2 \%$ rabbit anti-A. oligospora serum, and cultured at $26^{\circ} \mathrm{C}$ in light-free condition. After 3 days of culture, larval suspension (100 strips) of $H$. contortus was added to the plate. The traps and captured nematodes were counted under a light microscope after 12, 24, 36 and $48 \mathrm{~h}$, respectively. The numbers of traps and captured nematodes were calculated according to the references (Zhao et al. 2014; Zhang et al. 2017).

\section{Statistical analyses}

Statistical analyses were conducted using S.A.S. software Version 9.1 (S.A.S. Institute, Inc., Cary, NC, USA). A comparison of the number of captured nematode between different groups was performed using the Chi-square test. The values of $P<0.05$ were considered as statistically significant, while $P<0.01$ as an extremely significant difference. 


\section{Results}

cDNA of ADPl gene amplified from A. oligospora by RTPCR was about $500 \mathrm{bp}$ (Fig. 1). The sequencing results showed that the complete length of $A D P 1$ gene was $468 \mathrm{bp}$, which encoded 155 amino acids (Fig. 2). The sequences of ADP1 gene from A. oligospora XJ-A1 strain had been submitted to GenBank under accession numbers MT995855. The ADPl gene shared $96.37 \%$ identities in nucleotide and $94.19 \%$ identities in amino acid, respectively, when it was compared with the corresponding gene (AOL_s00210g23) of A. oligospora deposited in GenBank. The $A D P 1$ protein did contain signal peptide but owned a transmembrane region at amino acids 93-115 of this protein. Analysis of SWISS-MODEL software revealed that $A D P 1$ formed a cylindrical tertiary structure (Fig. 3).

The recombinant GFP-ADP1 (reADP1-GFP) and recombinant GFP (reGFP) proteins expressed in pET28aGFP-ADP and pET28a-GFP transformed $E$. coli DE3 strain after $6 \mathrm{~h}$ of induction with IPTG, showed the expected sizes of $50 \mathrm{kDa}$ and $30 \mathrm{kDa}$, respectively (Fig. 4 and 5) on SDSPAGE. Western blot analysis showed that the expressed 50 $\mathrm{kDa}$ recombinant protein could interact with rabbit anti$A D P 1$ serum, confirming the successful expression of reADP1-GFP (Fig. 2 and 4). SDS-PAGE analysis showed that the reADP1-GFP and reGFP purified with Ni-NTA affinity column had very high purity (Table 1; Fig. 5).

The collected $C$. elegans and $H$. contortus after incubation with purified reADP1-GFP for $1 \mathrm{~h}$ at $25^{\circ} \mathrm{C}$ showed green fluorescence on their surface, whereas those incubated with reGFP and BSA showed no green fluorescence on their surface under a fluorescence microscope (Fig. 6), confirming that only reADP1-GFP has adhesion activity on nematode surface. In contrast, reADPIGFP treated by trypsin lost its adhesion activity to the surface of nematode when compared to reADP1-GFP group, while PBS-treated reADP1-GFP did not reduce its adhesion activity to nematode (Fig. 6).

A. oligospora treated by anti-reADP1-GFP serum in the experimental group could produce three dimensional nets and capture nematodes as control group (Fig. 7A-D). Compared with the control group, there was no significant differences in the numbers of trap devices between experimental and control group $(P>0.05)$ (Fig. 7E). However, when treated by anti-reADP1-GFP serum for 48 $\mathrm{h}$, the numbers of captured nematodes of $A$. oligospora treated by anti-reADP1-GFP serum in the experimental group was significantly lower than that in the control group $(P<0.05)$ (Fig. 7F), which suggested that the nematodetrapping activity of $A$. oligospora could be inhibited by anti$A D P 1$ serum.

\section{Discussion}

As a model of NTF, A. oligospora enters the parasitic stage by forming complex three-dimensional networks to trap
Table 1: List of primer sequences used in this study

\begin{tabular}{|c|c|c|c|}
\hline $\begin{array}{l}\text { Primer } \\
\text { name }\end{array}$ & $\begin{array}{l}\text { Nucleotide sequence } \\
\left(5^{\prime} \rightarrow 3^{\prime}\right)\end{array}$ & $\begin{array}{l}\text { Target } \\
\text { gene }\end{array}$ & $\begin{array}{l}\text { Product } \\
\text { size (bp) }\end{array}$ \\
\hline P1 & CCGGAATTCATGTGTAAACCCTTCGAAATCG & ADP1 & 468 \\
\hline P1 & CCCAAGCTTTCATTTGACTTCATTAAGCTGCC & & \\
\hline P3 & ATGAGTAAAG GAGAAGAACTTTTCAC & GFP & 714 \\
\hline P4 & TTTGTGTCCAAGAATGTTTCCATC & & \\
\hline
\end{tabular}

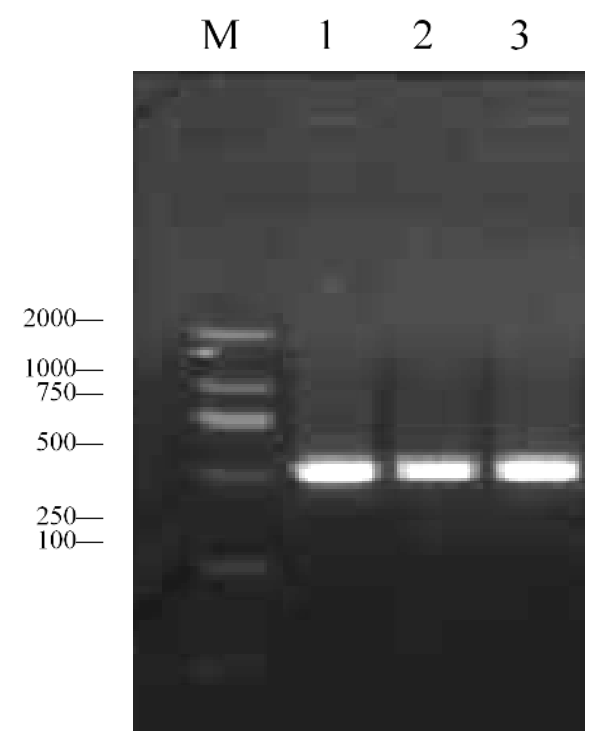

Fig. 1: Amplification of ADP1 gene of Arthrobotrys oligospora by RT-PCR

M: DNA marker (DL-2000), Lanes 1-3: RT-PCR products of ADPl gene

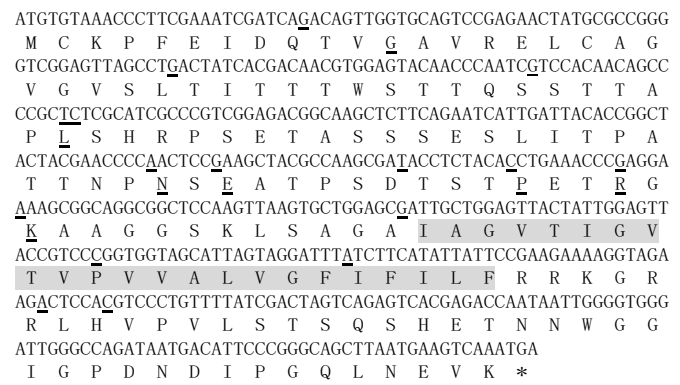

Fig. 2: Nucleotide sequence and amino acids of $A D P 1$ protein Note: The different amino acids were underlined; the amino acids constituting transmembrane region were shadowed

nematodes (Zhao et al. 2014). The trapping initiates a series of processes including adhesion, penetration, and immobilization of nematodes (Tunlid et al. 1994; Ahman et al. 1996; Minglian et al. 2004; Nordbring-Hertz et al. 2006; Yang et al. 2013; Liang et al. 2015; Liu et al. 2020). Adhesion is a premise for NTF preying nematodes. The research has shown that the adhesion process of NTF on C. elegans is a complex process requiring participation of carbohydrates, proteins, as well as their complexes and other substances (Tunlid and Jansson 1992). NordbringHertz et al. (2006) found that there were adhesion 


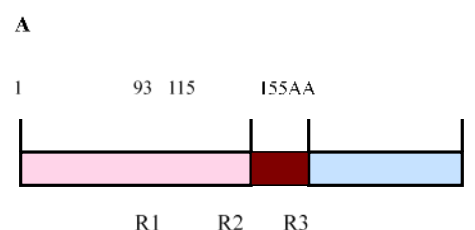

R1 R2 R3

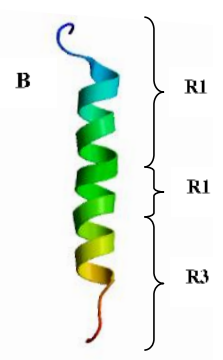

Fig. 3: Schematic diagram of molecular characteristics of $A D P 1$ protein of Arthrobotrys oligospora

A: Outside, transmembrane and inside regions of $A D P 1$ protein

B: Tertiary structure of $A D P 1$ protein

Note: R1: Outside region of membrane; R2: Transmembrane region; R3: Inside region of membrane

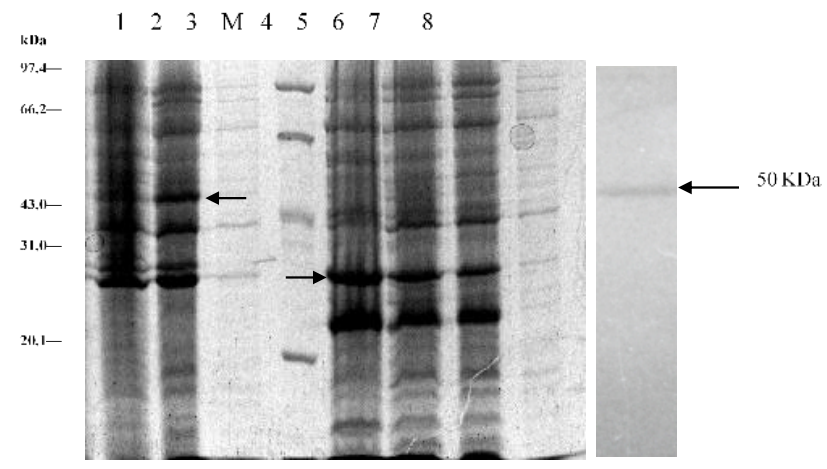

Fig. 4: SDS-PAGE and western blot analysis of the reADP1-GFP and $r e G F P$

M: Standard protein marker $(97.4,66.2,43.0,31.0,20.1 \mathrm{kDa})$; Lanes 1 and 2: Cell lysates of pET28a-GFP-ADP1 transformed E. coli after induced with IPTG for 4 and 6 hours, respectively

Lanes 3 and 7: Cell lysates of pET28a transformed $E$. coli after induced with IPTG for 4 and 6 hours, respectively; Lanes 4,5 and 6: Cell lysates of pET28a-GFP transformed $E$. coli after induced with IPTG
M
1
2
3

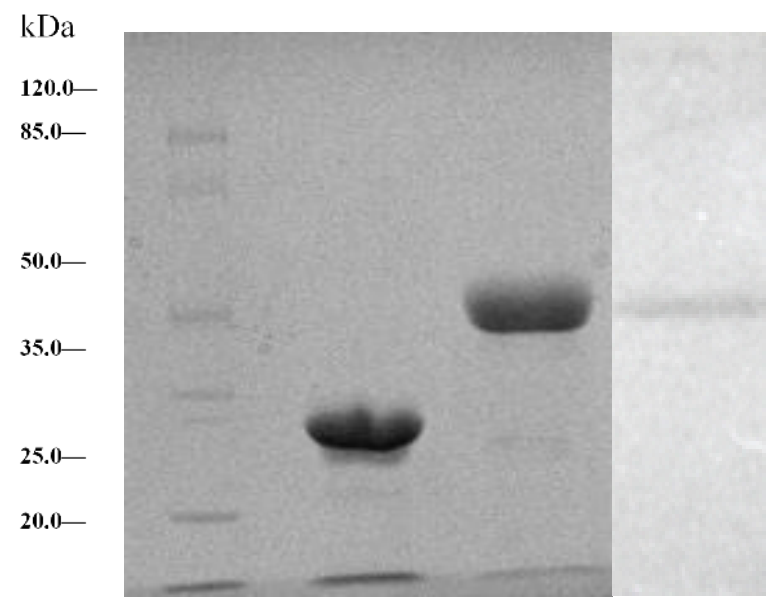

Fig. 5: SDS-PAGE and Western blot analysis of the reADP1$G F P$ and $r e G F P$

M: Standard protein marker (120.0, 85.0, 50.0, 35.0, 25.0, 20.0 kDa)

1: Purified $r e G F P$ protein

2: Purified reADPI-GFP protein

3: Western blot analysis of reADP1-GFP protein

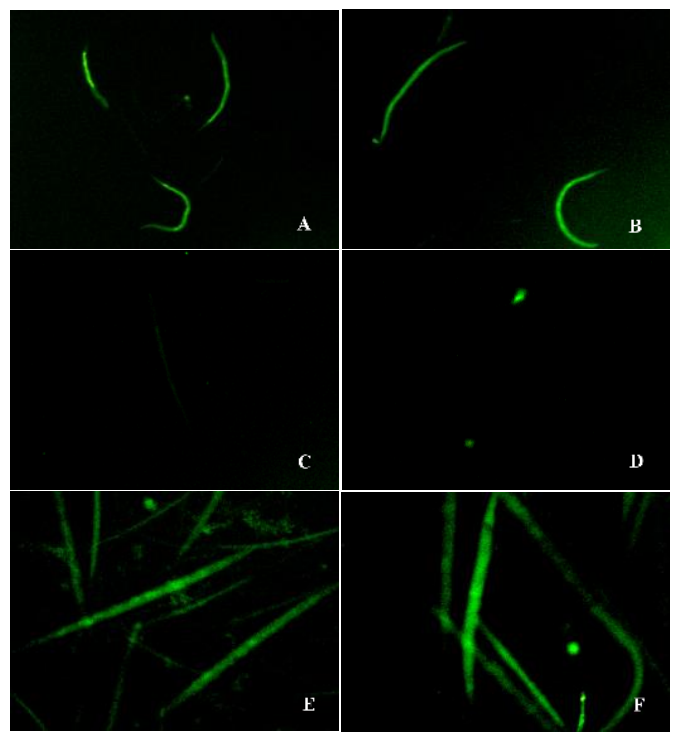

Fig. 6: Analysis of interaction of reADP1-GFP with nematodes A: reADP1-GFP interacts with C. elegans

B: reADPI-GFP interacts with $H$. contortus

C: BSA interacts with $H$. contortus

D: Trypsin treated reADPI-GFP interacts with $H$. contortus

E: PBS treated reADP1-GFP interacts with $H$. contortus

F: reADPI-GFP interacts with $H$. contortus
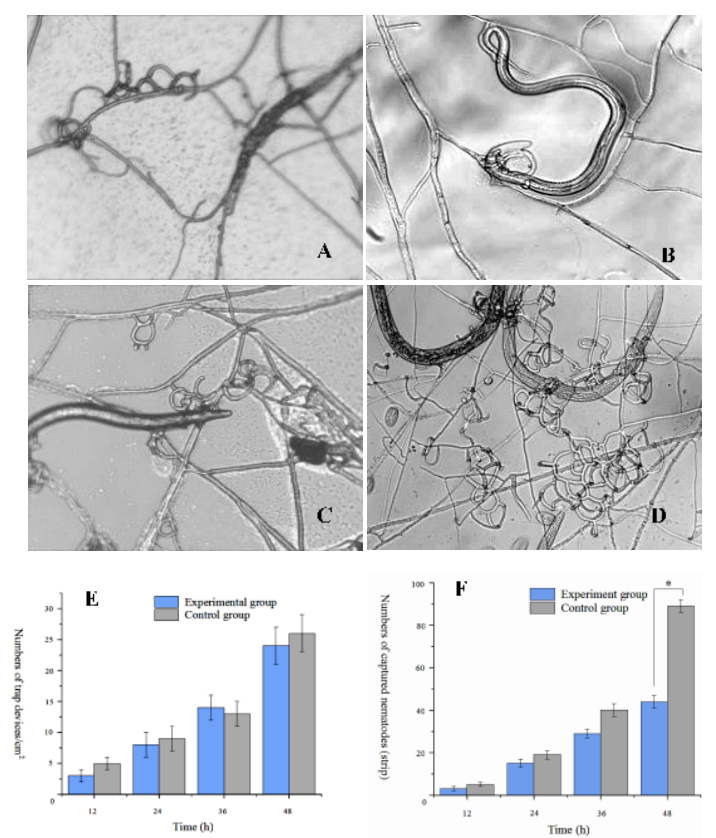

Fig. 7: Effects of anti-reADP1-GFP serum on the nematodetrapping activity of $A$. oligospora

A-D: The trap devices in $12 \mathrm{~h}, 24 \mathrm{~h}, 36 \mathrm{~h}$ and $48 \mathrm{~h}$ post-induction of larval suspension of $H$. contortus

$\mathbf{E}$ : The numbers of trap devices; $\mathbf{F}$ : The numbers of captured nematodes

substances between NTF and nematodes and confirmed that adhesion substances contain lectin. Meerupati et al. (2013) revealed that certain proteins also play important roles in the adhesion process. Yang et al. (2011) conducted whole genome analysis of A. oligospora and predicted that 17 genes were related to adhesion, among which, five genes 
were upregulated during the formation of their predatory organs, suggesting that some proteins may play important roles in the process of $A$. oligospora adhering to nematode (Yang et al. 2011). However, to date, the active adhesion substances produced by NTF and their underlying molecular mechanisms for adhesion are still incompletely understood (Meerupati et al. 2013; Liang et al. 2013).

Based on the studies on genomics and proteomics of $A$. oligospora, many new functional proteins have been identified and characterized (Li et al. 2016, 2017; Liang et al. 2017; Xie et al. 2019; Yang et al. 2018 Zhang et al. 2019). To better understand the biological functions of ADP1, interactions between A. oligospora $A D P 1$ and nematode were conducted. The results revealed that the reADP1-GFP protein could adhere to the surface of nematode and was unable to be washed away by elution buffer, suggesting that $A D P 1$ has adhesion function to nematodes. Furthermore, we confirmed that $A D P 1$ displayed stronger adhesion at $25^{\circ} \mathrm{C}$, which is in consistence with the natural environment of fungi, suggesting production of $A D P 1$ may be an environmental adaptability of fungi in the evolutionary process to form a favorable environment for its predation under natural conditions. In addition, trypsin digestion could block the adhesion ability of reADP1-GFP protein to nematode, while PBS did not affect its adhesion activity to the surface of nematode, which suggests that this novel protein ADP1 is involved in an adhesion role. The nematode-trapping activity of $A$. oligospora inhibited by anti-ADP1-GFP serum further confirmed that the $A D P 1$ protein was closely related to nematode-trapping process.

\section{Conclusion}

A. oligospora $A D P 1$ exerts an important role in the process of fungal adherence to nematodes, which provides new insights into our understanding of the molecular mechanisms of NTF preying nematodes.

\section{Acknowledgments}

This work was supported by National Natural Science Foundation of China (32060801 and 31460654) and National Key Research and Development Program (No. 2017YFD0501200). The authors thank the staff for providing the materials for this study.

This work was supported by National Natural Science Foundation of China (32060801, 31460654), National Key Research and Development Program (No. 2017YFD0501200).

\section{Author Contributions}

Li Jie and Meng Qingling planned and designed the whole study. Chen Shuangqing, Li zhiyuan, Wang Lixia, Shang Yunxia, Gong Shasha, Xiao Chencheng, Zhang Kai performed and completed the experiments. Li Jie, Qiao Jun and Meng Qingling wrote the manuscript. Zhang Xingxing and Cai Xuepeng reviewed and revised the manuscript. All authors read and approved the final manuscript.

\section{Conflict of Interest}

This manuscript has not been simultaneously submitted for publication in another journal and been approved by all coauthors. The authors declare that they do not have any conflict of interest.

\section{Data Availability}

Data presented in this study are available on fair request to the corresponding author.

\section{Ethics Approval}

The experiments were carried out in accordance with the guidelines issued by the Ethical Committee of Shihezi University.

\section{References}

Ahman J, B Ek, L Rask, A Tunlid (1996). Sequence analysis and regulation of a gene encoding a cuticle-degrading serine protease from the nematophagous fungus Arthrobotrys oligospora. Microbiology 142:1605-1616

Alvarez L, A Lifschitz, C Entrocasso, J Manazza, L Mottier, B Borda, G Virkel, C Lanusse (2008). Evaluation of the interaction between ivermectin and albendazole following their combined use in lambs. J Vet Pharmacol Ther 31:230-239

Andersson KM, D Kumar, J Bentzer, E Friman, D Ahrén, A Tunlid (2014). Interspecific and host-related gene expression patterns in nematodetrapping fungi. BMC Genom 15:968-982

Bird J, RP Herd (1995). In vitro assessment of two species of nematophagous fungi (Arthrobotrys oligospora and Arthrobotrys flagrans) to control the development of infective cyathostome larvae from naturally infected horses. Vet Parasitol 56:181-187

Chandrawathani P, J Omar, PJ Waller (1998). The control of the free-living stages of Strongyloides papillosus by the nematophagous fungus, Arthrobotrys oligospora. Vet Parasitol 76:321-335

Fernández AS, E Henningsen, M Larsen, P Nansen, J Grønvold, J Søndergaard (1999). A new isolate of the nematophagous fungus Duddingtonia flagrans a biological control agent against free-living larvae of horse strongyles. Equine Vet J 31:488-491

Flores-Crespo J, D Herrera-Rodríguez, PMD Gives, E Liébano-Hernández, VM Vázquez-Prats, ME López-Arellano (2003). The predatory capability of three nematophagous fungi in the control of Haemonchus contortus infective larvae in ovine faeces. J Helminthol 77:297-303

Gives PMD, VM Vazquez-Prats (1994). Reduction of Haemonchus contortus infective larvae by three nematophagous fungi in sheep faecal cultures. Vet Parasitol 55:197-203

Grønvold J, J Wolstrup, M Larsen, SA Henriksen, P Nansen (1993). Biological control of Ostertagia ostertagi by feeding selected nematode-trapping fungi to calves. J Helminthol 67:31-36

Hay FS, JH Niezen, C Miller, L Bateson, H Robertson (1997). Infestation of sheep dung by nematophagous fungi and implications for the control of free-living stages of gastrointestinal nematodes. Vet Parasitol 70:247-254

Kaewthamasorn M, S Wongsamee (2006). A preliminary survey of gastrointestinal and haemoparasites of beef cattle in the tropical livestock farming system in Nan Province, northern Thailand. Parasitol Res 99:306-308 
Li J, Y Liu, H Zhu, KQ Zhang (2016). Phylogenic analysis of adhesion related genes Mad1 revealed a positive selection for the evolution of trapping devices of nematode-trapping fungi. Sci Rep 6; Article 22609

Li X, YQ Kang, YL Luo, KQ Zhang, CG Zou, LM Liang (2017). The NADPH oxidase AoNoxA in Arthrobotrys oligospora functions as an initial factor in the infection of Caenorhabditis elegans. $J$ Microbiol 55:885-891

Liang L, H Gao, J Li, L Liu, Z Liu, KQ Zhang (2017). The Woronin body in the nematophagous fungus Arthrobotrys oligospora is essential for trap formation and efficient pathogenesis. Fung Biol 121:11-20

Liang L, R Shen, Y Mo, J Yang, X Ji, KQ Zhang (2015). A proposed adhesin AoMad1 helps nematode-trapping fungus Arthrobotrys oligospora recognizing host signals for life-style switching. Fung Genet Biol 81:172-181

Liang L, H Wu, Z Liu, R Shen, H Gao, J Yang, K Zhang (2013). Proteomic and transcriptional analyses of Arthrobotrys oligospora cell wall related proteins reveal complexity of fungal virulence against nematodes. Appl Microbiol Biotechnol 97:8683-8692

Liu K, W Zhang, Y Lai, M Xiang, X Wang, X Zhang, X Liu (2014). Drechslerella stenobrocha genome illustrates the mechanism of constricting rings and the origin of nematode predation in fungi. BMC Genom 15; Article 114

Liu M, X Cheng, J Wang, D Tian, K Tang, T Xu, M Zhang, Y Wang, M Wang (2020). Structural insights into the fungi-nematodes interaction mediated by fucose-specific lectin AofleA from Arthrobotrys oligospora. Intl J Biol Macromol 164:783-793

Liu T, DW Tian, LJ Zou, FY Liu, QY Can, JK Yang, JP Xu, XW Huang, JQ Xi, ML Zhu, MH Mo, KQ Zhang (2018). Quantitative proteomics revealed partial fungistatic mechanism of ammonia against conidial germination of nematode-trapping fungus Arthrobotrys oligospora ATCC24927. Intl J Biochem Cell Biol 98:104-112

Meerupati T, KM Andersson, E Friman, D Kumar, A Tunlid, D Ahrén (2013). Genomic mechanisms accounting for the adaptation to parasitism in nematode-trapping fungi. PLoS Genet 9; Article e1003909

Minglian Z, M Minghe, Z Keqin (2004). Characterization of a neutral serine protease and its full-length cDNA from the nematode-trapping fungus Arthrobotrys oligospora. Mycologia 96:16-22

Nordbring-Hertz B, HB Jansson, A Tunlid (2006). Nematophagous fungi. In Encyclopedia of Life Sciences. John Wiley \& Sons Ltd., New York, USA

Sréter T, V Molnár, T Kassai (1994). The distribution of nematode egg counts and larval counts in grazing sheep and their implications for parasite control. Intl J Parasitol 24:103-108
Tembely S, A Lahlou-kassi, JE Rege, S Sovani, ML Diedhiou, RL Baker (1997). The epidemiology of nematode infections in sheep in a cool tropical environment. Vet Parasitol 70:129-141

Terrill TH, JE Miller, JM Burke, JA Mosjidis, RM Kaplan (2012), Experiences with integrated concepts for the control of Haemonchus contortus in sheep and goats in the United States. Vet Parasitol 186:28-37

Tunlid A, HB Jansson (1992), Nordbring-Hertz B. Fungal attachment to nematodes. Mycol Res 96:401-412

Tunlid A, S Rosén, B Ek, L Rask (1994). Purification and characterization of an extracellular serine protease from the nematode-trapping fungus Arthrobotrys oligospora. Microbiology 140:1687-1695

Xie M, Y Wang, L Tang, L Yang, D Zhou, Q Li, X Niu, KQ Zhang, J Yang (2019). AoStuA, an APSES transcription factor, regulates the conidiation, trap formation, stress resistance and pathogenicity of the nematode-trapping fungus Arthrobotrys oligospora. Environ Microbiol 21:4648-4661

Yang J, Y Yan, L Juan, Z Wei, G Zongyi, J Dewei, W Yunchuan, Z Ke-Qin (2013). Characterization and functional analyses of the chitinaseencoding genes in the nematode-trapping fungus Arthrobotrys oligospora. Arch Microbiol 195:453-462

Yang J, L Wang, X Ji, Y Feng, X Li, C Zou, J Xu, Y Ren, Q Mi, J Wu, S Liu, Y Liu, X Huang, H Wang, X Niu, J Li, L Liang, Y Luo, K Ji, W Zhou, Z Yu, G Li, Y Liu, L Li, M Qiao, L Feng, KQ Zhang (2011). Genomic and proteomic analyses of the fungus Arthrobotrys oligospora provide insights into nematode-trap formation. PLoS Pathog 7; Article e1002179

Yang X, N Ma, L Yang, Y Zheng, Z Zhen, Q Li, M Xie, J Li, KQ Zhang, J Yang (2018). Two Rab GTPases play different roles in conidiation, trap formation, stress resistance, and virulence in the nematodetrapping fungus Arthrobotrys oligospora. Appl Microbiol Biotechnol 102:4601-4613

Zhang D, X Zhu, F Sun, K Zhang, S Niu, X Huang (2017). The roles of actin cytoskeleton and actin-associated protein Crnlp in trap formation of Arthrobotrys oligospora. Res Microbiol 168:655-663

Zhang W, C Hu, M Hussain, J Chen, M Xiang, X Liu (2019). Role of lowaffinity calcium system member Figl homologous proteins in conidiation and trap-formation of nematode-trapping fungus Arthrobotrys oligospora. Sci Rep 9; Article 4440

Zhao X, Y Wang, Y Zhao, Y Huang, KQ Zhang, J Yang (2014). Malate synthase gene AoMls in the nematode-trapping fungus Arthrobotrys oligospora contributes to conidiation, trap formation, and pathogenicity. Appl Microbiol Biotechnol 98:2555-2563 